\title{
Effects of amphetamine administration on neurogenesis in adult rats
}

\author{
Tomasz Stępieñ ${ }^{1}$, Ewa Taracha² ${ }^{2}$ Ewelina Kaniuga ${ }^{2}$, Adam Płaźnik ${ }^{2}$, Teresa Wierzba-Bobrowicz ${ }^{1}$ \\ ${ }^{1}$ Department of Neuropathology, Institute of Psychiatry and Neurology, Warsaw, ${ }^{2}$ Department of Neurochemistry, \\ Institute of Psychiatry and Neurology, Warsaw, Poland
}

\begin{abstract}
In our study expression of phospho-(Ser-10)-histone $\mathrm{H} 3\left(\mathrm{pH}_{3 \mathrm{~S}} 10\right.$ ), a marker for the early stage of neurogenesis, and cellular early response genes were investigated using c-Fos protein as an example of a transcription factor in the neurogenic process in rats. Neurogenesis in the adult brain is regulated by endo- and exogenous factors, which influence the proliferation potential of progenitor cells and accelerate the dendritic development of newborn neurons. $D$-amphetamine, a psychoactive substance, is one of the exogenous factors able to influence the process of neurogenesis. The rats were injected with D-amphetamine at a dose of $1.5 \mathrm{mg} / \mathrm{kg} / \mathrm{body}$ weight (b.w.) under one administration scheme. Analysis of the $\mathrm{pH}_{3 \mathrm{~S}_{10}}$ and $\mathrm{c}$-Fos expression levels in the group of $\mathrm{D}$-amphetamine administered rats provided evidence of enhanced expression of these proteins in the regions of neurogenesis occurrence in rats. However, conclusions concerning stimulant effects of amphetamine on neurogenesis should be formulated with great caution, taking into account amphetamine dosage and the administration scheme. It should also be remembered that doses of psychoactive substances used in animal models can be lethal to humans.
\end{abstract}

Key words: neurogenesis, neural stem cells, neuronal progenitor cells, DG, SVZ.

\section{Introduction}

Neurogenesis in the adult brain is not a simple continuation of embryonic neurogenesis. During adulthood neurons are not born in such a huge number and do not migrate over such long distances in different directions. Groundbreaking animal investigations carried out in the 1960s resulted in the identification of undifferentiated neural stem cells (NSCs) [3]. Two locations, the hippocampal dentate gyrus (DG) and the subventricular zone (SVZ), in which neurogenesis takes place, have been identified in the adult mammalian brain. During the neurogenic process in the adult brain neurons newly born in the subventricular zone migrate to the olfactory bulb, while those born in the dentate gyrus migrate locally [14]. Some studies also indicate the presence of neural stem cells (NSCs) in other regions of the brain, the frontal and temporal cortex, tonsillar body and the subcortical white body $[20,26]$.

In neurogenesis in the adult brain with NSCs, apart from neurons, glial astrocytes and oligodendrocytes are also generated. New neurons generated from NSCs undergo consecutive developmental stages. Firstly, they become neuronal progenitor cells (NPCs) and neuroblasts, then immature neurons and finally they take the form of neurons. In the DG granular layer 
three types of transcription active cells have been identified: radial glia-like matrix cells with expression of glial fibrillary acidic protein (GFAP) and Sox 2 (type I); non-process bearing cells with nestin and Tis-21 expression (type II), also known as transiently active progenitor cells; and neuroblasts (type III ) with DCX protein (doublecortin) and Ki67 expression, and immature neurons with expression of DCX, PSANCAM protein, marker of migrating neurons (polysialylated neuronal cell adhesion molecule) and neuron-specific protein (NeuN) [5,12]. Also in the subventricular zone three types of cells have been identified: type B cells, GFAP-positive neural stem cells (NSCs); type C cells with expression of Mash1 protein; and neuroblasts (type A) with expression of DCX protein [24].

Neurogenesis in the adult brain is regulated by endo- and exogenous factors, which influence the proliferation potential of progenitor cells and accelerate the dendritic development of newborn neurons [41]. D-amphetamine, a psychoactive substance, is one of the exogenous factors able to influence the process of neurogenesis. The results of individual studies in this area, published so far, have been conflicting. Some of them indicate that D-amphetamine administration does not exert an effect on proliferation and/or survival of newborn neurons in the dentate gyrus in the mammalian model [6], while others reveal that psychostimulants diminish the level of neurogenesis in the adult brain $[19,40,43]$.

Phosphorylation of the $\mathrm{N}$-terminal $\mathrm{H} 3$ histone domain in the Ser-10 position $\left(\mathrm{pH}_{3} \mathrm{~S}_{10}\right)$ and/or Ser-28 position destabilises chromatin, directly preceding replication and transcription. Histone $\mathrm{H} 3$ is a very widespread marker of early stages of neurogenesis. Unlike DCX, $\mathrm{pH}_{3 \mathrm{~S}_{10}}$ expression takes place only in newborn cells $[23,28]$. Due to the external factor activity, gene activation of early cellular response occur in parallel with histone $\mathrm{H} 3$ phosphorylation, e.g., $c$-fos genes. The same kinase, mitogen-activated protein kinase (MAPK), is responsible for both processes $[7,9,18]$. The product of the c-fos gene is a good marker for neuron activation in the mechanism of neuroadaptation [21,25].

The aim of our study was to establish the levels of $\mathrm{pH}_{3 \mathrm{~S}_{10}}$ expression and the early cellular response of genes as markers for transcription, using c-Fos protein as an example in the process of neurogenesis in a group of rats administered D-amphetamine by injection.

\section{Material and methods}

In our research we used two groups: the study group composed of 8 rats receiving amphetamine according to a two-injection sensitisation protocol with a booster dose (TIPS), and the control group of 6 rats not exposed to amphetamine. The rats received a single dose of amphetamine (1.5 mg/kg/day). After a 6-day interval, the same dose of D-amphetamine was given once a day for 7 days. Following a 14-day interval after amphetamine administration the rats were given a single booster dose $(1.5 \mathrm{mg} /$ $\mathrm{kg} /$ day) of amphetamine, $2 \mathrm{~h}$ before decapitation. Under this scheme a single dose of amphetamine initiates the process of permanent neuroadaptation changes. These changes become apparent at the behavioural and biochemical level in response to a second dose $[35,39]$. D-amphetamine sulfate (Sigma, St. Louis, MO, USA) was dissolved $(1.5 \mathrm{mg} / \mathrm{ml})$ in sterile aqueous $0.9 \% \mathrm{NaCl}$ solution (Sal; Polpharma, Starogard Gdański, Poland) and injected intraperitoneally (i.p.) at a dose of $1.5 \mathrm{mg} / \mathrm{kg}$ body weight (b.w.).

All animal use procedures were performed in accordance with both the European Communities Council Directive of November 24, 1986 on the protection of laboratory animals (86/609/EEC), and with the current laws of Poland, and were approved by the Bioethical Committee of the Medical University of Warsaw (Certificate of Approval No. 47/2012).

\section{Immunochemistry}

The rats were decapitated and the brains were fixed in $10 \%$ buffered formalin. The material was washed in $70 \%$ ethanol for $2 \mathrm{~h}$, then in $96 \%$ ethanol for $12 \mathrm{~h}$, twice in $100 \%$ ethanol for $12 \mathrm{~h}$ and twice in xylene for $12 \mathrm{~h}$. After fixing the brains were embedded in paraffin for $48 \mathrm{~h}$. The material was then cut serially in $5 \mu \mathrm{m}$ slices on the rotary microtome onto silane-coated glass slides (Silan Sigma A36648), deparaffinized in xylene $3 \times 10 \mathrm{~min}$, released in a decreasing ethyl alcohol series, $100 \%, 96 \%$ and $70 \%$, for $10 \mathrm{~min}$ and rinsed in distilled water for $10 \mathrm{~min}$. Epitopes were exposed to a temperature of $100^{\circ} \mathrm{C}$ $3 \times 5$ min in citrate buffer ( $\mathrm{pH} \mathrm{6.0),} \mathrm{cooled} \mathrm{at} \mathrm{room}$ temperature for $10 \mathrm{~min}$ and rinsed in distilled water for $10 \mathrm{~min}$. This was followed by blocking endogenous peroxidase in $0.3 \%$ TRIS $+\mathrm{H}_{2} \mathrm{O}_{2}$ (TrisBase T1503, pH 7.4-7.6) for $10 \mathrm{~min}$. Then they were rinsed in TRIS for $10 \mathrm{~min}$ and blocked with serum NORMAL HORSE SERUM 2.5\% (VECTOR PK-7200) for $1 \mathrm{~h}$. Specimens 
A

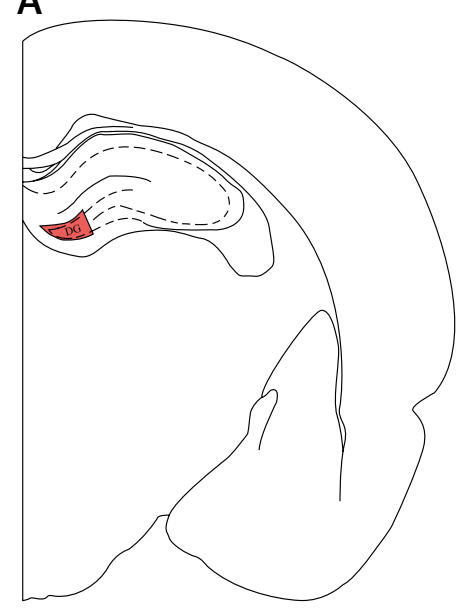

B

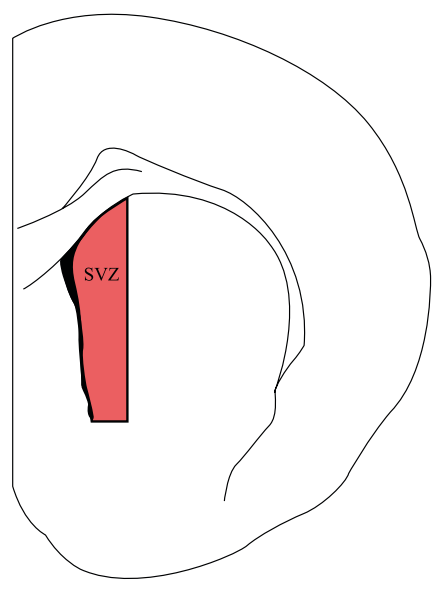

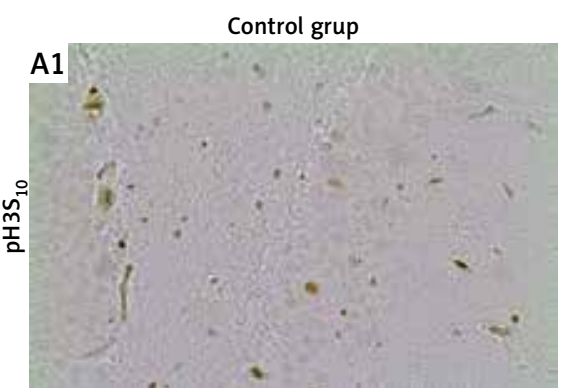

A3
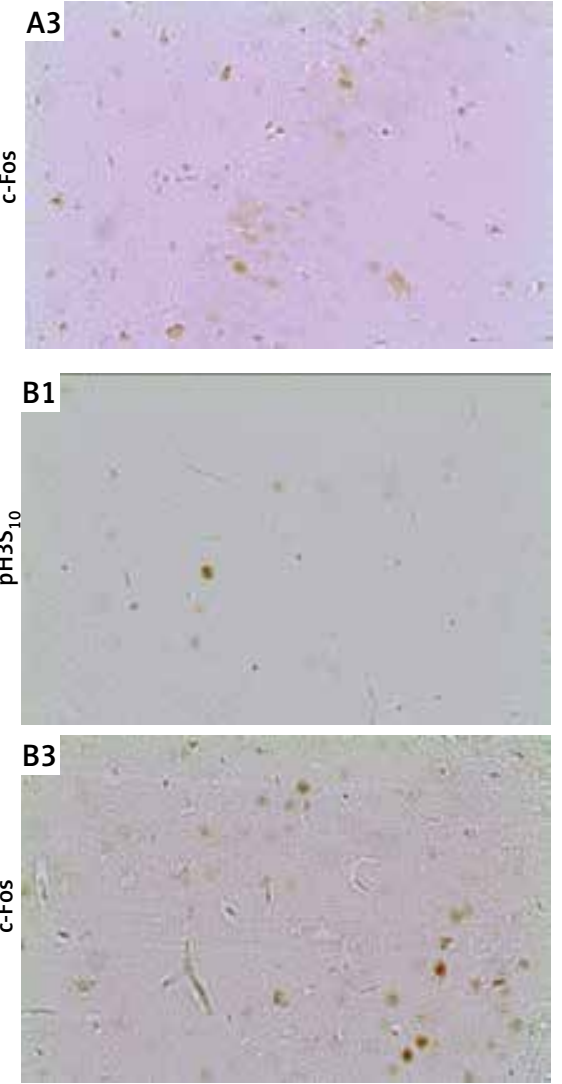

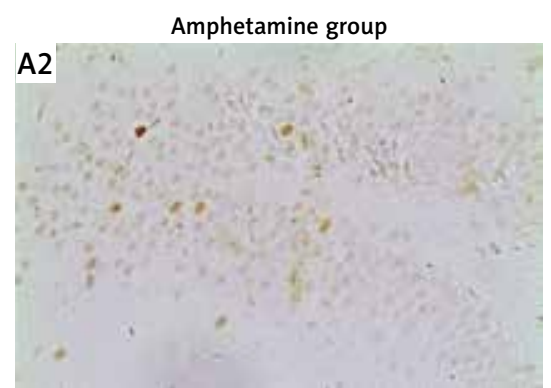

A4
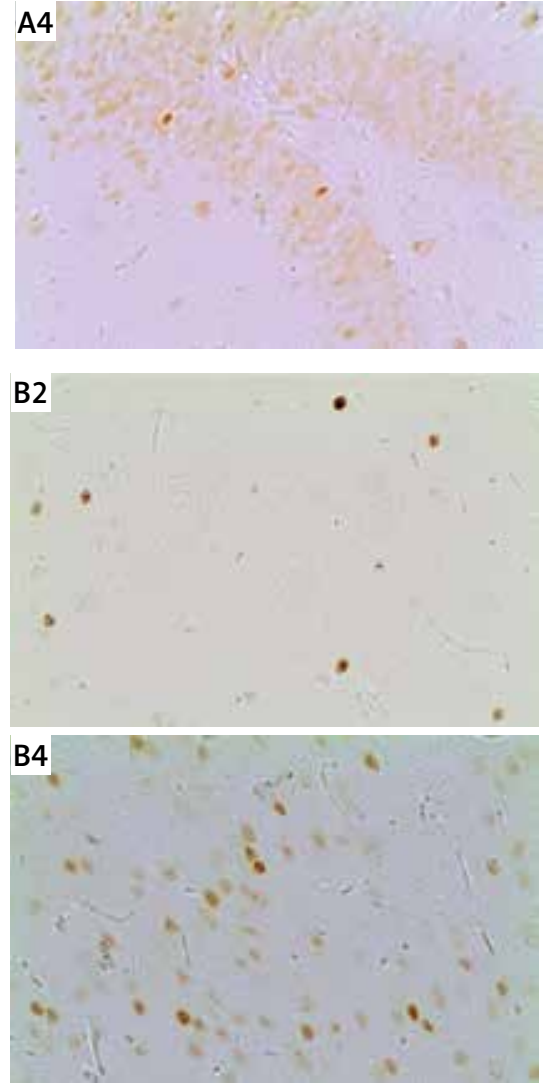

Fig. 1. Quantitative analysis of c-Fos and $\mathrm{pH}_{3} \mathrm{~S}_{10}$ proteins in immunopositive cells. A) Scheme of analysed dentate gyrus (DG). A1-A2 show pH3S ${ }_{10}$ expression in DG in control and amphetamine groups. A3-A4 show c-Fos expression in DG in control and amphetamine groups. B) Scheme of analysed subventricular zone (SVZ). B1-B2 show expression of $\mathrm{pH}_{3 \mathrm{~S}_{10}}$ in SVZ in control and amphetamine groups. B3-B4 show expression of C-Fos in SVZ in control and amphetamine groups.

were incubated with c-Fos antibody $(1: 700)$ (sc-253, Santa Cruz Biotechnology) or with phospho-(Ser10)-histone $\mathrm{H} 3$ (pH3S $_{10}$ ) antibody (1: 50) (sc-8656-R, Santa Cruz Biotechnology) for 50 min in $2 \%$ serum NORMAL HORSE SERUM. Then the following procedures were applied: rinsing in TRIS for minimum $40 \mathrm{~min}$, incubation in biotinylated anti-rabbit IgG (Victor PK-7200) for at least 25 min, rinsing in TRIS for minimum 40 min, incubation in Vectastain RTV Elite $A B C$ Reagent (PK-7200) for minimum 25 min, incubation in chromogen DAB (Sigma, D5637-5G) for 0-3 min, rinsing in distilled water for $10 \mathrm{~min}$, dehydration in two ethyl alcohols, $96 \%$ and $100 \%$, respectively, for $10 \mathrm{~min}$, rinsing in xylene $2 \times 10 \mathrm{~min}$ and sizing of Histokitt specimens (MarFour 1025/500).

\section{Quantitative analysis}

The cells were counted in the hippocampal dentate gyrus (DG, Bregma $-3.3 \mathrm{~mm}$ ) and the subventricular zone (SVZ, Bregma $+1.00 \mathrm{~mm}$ ). c-Fos and pH3S 10 immu- 


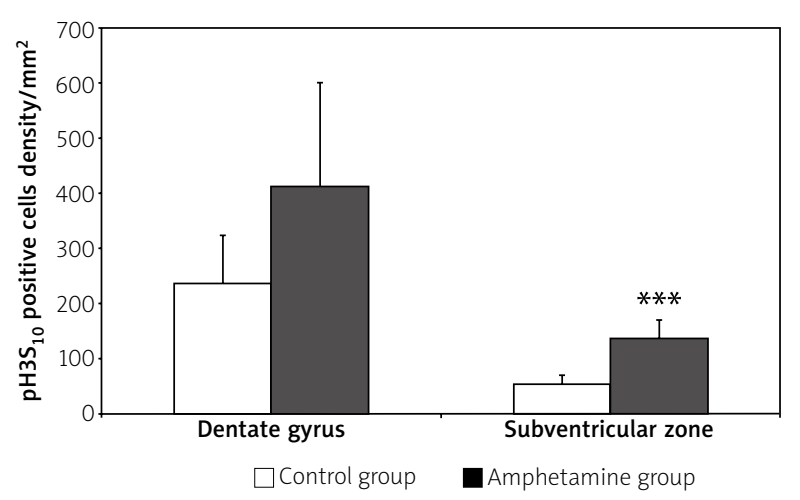

Fig. 2. Density of phospho-(Ser-10)-histone H3 $\left(\mathrm{pH}_{3 \mathrm{~S}_{10}}\right)$ immunoreactivity in cells in dentate gyrus and subventricular zone after amphetamine administration. ${ }^{* * *} p<0.001$.

nostaining was quantified at $\times 100$ magnification, using an Olympus BX-51 microscope with a DP-70 (Olympus) camera and CellSens Dimension imaging software (Olympus Soft Imaging Solutions $\mathrm{GmbH}$, Munster, Germany). Positive nuclei were counted and averaged for the two serial slices for statistical analysis.

\section{Statistical analysis}

In the statistical analysis of the results the Mann-Whitney $U$ test was used. A value of $p \leq 0.05$ was considered to indicate statistical significance. The results were analyzed using STATISTICA 12 software.

\section{Results}

Expression of c-Fos and $\mathrm{pH}_{3 \mathrm{~S}_{10}}$ proteins in cells of the subventricular zone and hippocampal dentate gyrus in the left cerebral hemisphere was analyzed. We observed transcription active cells with marked nuclei. The analysis of c-Fos protein expression $(605.31 \pm 147.39, p<0.00002)$ and $\mathrm{pH}_{3 S_{10}}(134.61$ $\pm 4.32, p<0.0002)$ in the SVZ cells showed a statistically significantly higher number of transcription active cells in the D-amphetamine administered rats compared to the control group, while the quantitative analysis of cells in the DG revealed an upward tendency in the number of transcription active cells in rats given D-amphetamine (Table I).

\section{Discussion}

In our experiment rats were given D-amphetamine at a dose of $1.5 \mathrm{mg} / \mathrm{kg} / \mathrm{b} . \mathrm{w}$. In the study group

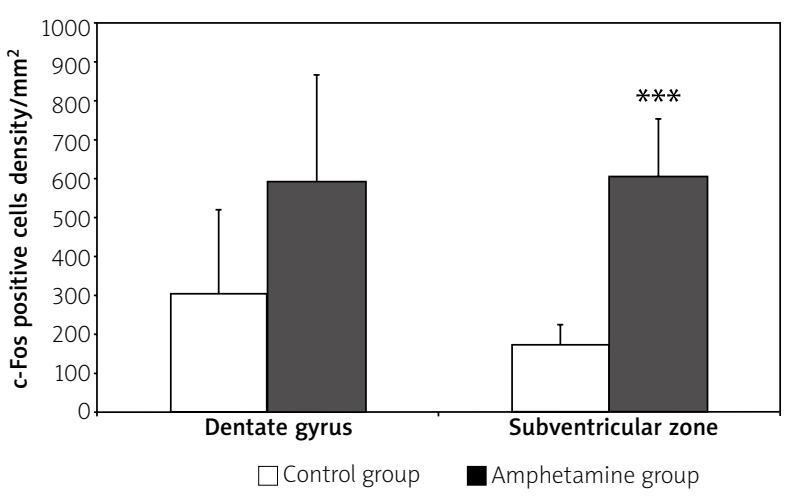

Fig. 3. Density of c-Fos immunoreactivity in cells in dentate gyrus and subventricular zone after amphetamine administration. ${ }^{* * *} p<0.001$.

the results showed a significantly higher density of newborn cells (NSCS, NPCs) in the subventricular zone. However, there were no significant differences in the density of NSCs and NPCs between the study and control groups in the hippocampal dentate gyrus. Neurogenesis in adult brain is regulated by numerous factors which affect the proliferation potential in progenitor cells and accelerate the dendritic development of newborn neurons [41]. Two markers, c-Fos and $\mathrm{pH}_{3 \mathrm{~S}_{10}}$ proteins, were used to identify transcription active cells. Animal studies show that a stimulant-rich environment stimulates the process of neurogenesis and enhances c-Fos expression in the hippocampal dentate gyrus [34,36]. The highest level of $\mathrm{pH}_{3 \mathrm{~S}_{10}}$ was observed 30 min after amphetamine injection, while increased mRNA encoding c-Fos was found after 30-90 min [30]. Expression of $\mathrm{pH}_{3} \mathrm{~S}_{10}$ was observed only in newborn cells (NSCS, NPCS) in phases $G 2$ and $M[1,28,38]$. Stress, eating habits, physical activity, alcohol and drugs are listed among factors affecting the dynamics of neurogenesis and total amount of neurons $[13,32]$.

In the mammalian model D-amphetamine, as a psychoactive agent, affects proliferation and/or survival of newborn neurons in the hippocampal dentate gyrus [6]. The results of the experiment indicate that psychostimulants can reduce the level of neurogenesis in the brains of adult rats $[19,40,43]$. Experimental data revealed a destructive effect of high D-amphetamine doses on dopaminergic nerve endings and apoptosis stimulation $[4,10]$. However, little is known about the effect of small D-amphetamine doses on the brain functions. It is suggest- 
Table I. Comparison of c-Fos and $\mathrm{pH}_{3 \mathrm{~S}_{10}}$ cell density between control and amphetamine groups in dentate gyrus (DG) and subventricular zone (SVZ). ${ }^{* * *} p<0.001$ (Mann-Whitney $U$ test)

\begin{tabular}{lcccccccccc}
\hline & $\begin{array}{c}\text { Mean - } \\
\text { control } \\
\text { group }\end{array}$ & $\begin{array}{c}\text { Mean - } \\
\text { amphetamine } \\
\text { group }\end{array}$ & $t$ & $d f$ & $p$ & $\begin{array}{c}\text { SD - } \\
\text { control } \\
\text { group }\end{array}$ & $\begin{array}{c}\text { SD - } \\
\text { amphetamine } \\
\text { group }\end{array}$ & Qquotient $F$ & $p$ \\
variance & variance \\
\hline DG pH3S10 & 236.17 & 410.76 & -1.89 & 10 & 0.0867 & 87.24 & 189.72 & 4.73 & 0.15 \\
\hline SVZ pH3S10 & 53.22 & $134.61^{\text {** }}$ & -5.20 & 12 & 0.0002 & 16.89 & 35.12 & 4.32 & 0.13 \\
\hline SVZ c-FoS & 173.99 & $605.31^{\text {** }}$ & -6.81 & 12 & 0.00002 & 50.62 & 147.39 & 8.48 & 0.03 \\
\hline DG c-FoS & 305.48 & 592.05 & -2.10 & 12 & 0.0571 & 215.19 & 275.49 & 1.64 & 0.61 \\
\hline
\end{tabular}

ed that D-amphetamine stimulates the activity of newborn neurons and dynamics of neurogenesis $[11,29]$.

The mechanism by which D-amphetamine exerts its effect on the development and differentiation of new neurons includes the neurotrophin activation pathway. Neurotrophins regulate proliferation, differentiation and neuroplasticity. They are also responsible for the release of neurotransmitters and expression of their receptors. Trophic factors exert a major effect on neuronal survival, differentiation and maturation [2,15]. Neurotrophins comprise nerve growth factor (NGF), brain-derived neurotrophic factor (BDNF), glial cell-derived neurotrophic factor (GDNF), neurotrophin 3 (NT3) and neurotrophin 4/5 (NT 4/5). Neurotrophins react with cells via receptors p75 and Trk. Reaction of neurotrophins with receptor p75 leads to cellular apoptosis, while neurotrophin-Trk receptor binding stimulates neuronal survival and differentiation [8]. BDNF plays a key role in the regulation of neuroplasticity in the adult human brain [17]. It has been evidenced that BDNF infusion into the hippocampus promotes neurogenesis [33]. There are numerous data underlying the crucial role of BDNF in the regulation of neurogenesis in the dentate gyrus of the adult brain. BDNF binds multiple receptors, e.g., p75 or Trk. The mechanism by which BDNF stimulates TrkB expression in precursor cells still remains unclear [31,42].

These findings correspond to those obtained for even higher doses of amphetamine. D-amphetamine administered to Sprague-Dawley rats at a dose of $2.5 \mathrm{mg} / \mathrm{kg}$ for 14 days did not affect the proliferation and survival of newborn neurons in the dentate gyrus [6]. It is likely that this result is influenced by the fact that amphetamine can contribute to the diminished volume of the hippocampus [38]. The studies evidenced that administration of methamphetamine enhances the proliferation of neuronal progenitor cells and their survival in the hippocampal dentate gyrus [22]. On the other hand, several in vivo models of METH exposure have demonstrated decreases in hippocampalneurogenesis[16,19,37]. METH-induced oxidative stress and nitrosylation have also been shown to increase apoptosis and decrease neural progenitor cell proliferation in the dentate gyrus of the hippocampus [40]. The comparison of different results supports the conclusion that the effect of amphetamine depends on the dosage and administration scheme [19]. Experiments on methamphetamine self-administration in a mammalian model show that short episodes of administration (for $1 \mathrm{~h}$ twice weekly (intermittent short access, I-ShA) and $1 \mathrm{~h}$ daily (short access ShA)) increase the number of cells in S phase, c-Fos positive in the DG [27].

This may suggest that our protocol of amphetamine administration falls within the definition of a short exposure to amphetamine. An analysis of $\mathrm{pH}_{3 \mathrm{~S}_{10}}$ and $\mathrm{c}$-Fos expression levels in D-amphetamine administered rats provides evidence of enhanced expression of these proteins in the regions in which neurogenesis occurs. Conclusions on the stimulating effect of amphetamine on neurogenesis should be formulated with great caution, having also in mind that doses of psychoactive substances applied in the animal model may be lethal to humans.

\section{Acknowledgments}

The study was supported by the National Science Centre of Poland grant No. UMO-2015/19/B/ NZ7/03610 and by the Institute of Psychiatry and Neurology statutory fund No. 501-003-15017 and 501-071-17021.

\section{Disclosure}

Author reports no conflict of interest. 


\section{References}

1. Abrous DN, Koehl M, Le Moal M. Adult neurogenesis: from precursors to network and physiology. Physiol Rev 2005; 85: 523 569.

2. Akerud P, Alberch J, Eketjall S, Wagner J, Arenas E. Differential effects of glial cell line-derived neurotrophic factor and neurturin on developing and adult substantia nigra dopaminergic neurons. J Neurochem 1999; 73: 70-78.

3. Altman J, Das GD. Post-natal origin of microneurones in the rat brain. Nature 1965; 207: 953-956.

4. Atianjoh FE, Ladenheim B, Krasnova IN, Cadet JL. Amphetamine causes dopamine depletion and cell death in the mouse olfactory bulb. Eur J Pharmacol 2008; 589: 94-97.

5. Attardo A, Fabel K, Krebs J, Haubensak W, Huttner WB, Kempermann G. Tis21 expression marks not only populations of neurogenic precursor cells but also new postmitotic neurons in adult hippocampal neurogenesis. Cereb Cortex 2010; 20: 304-314.

6. Barr JL, Renner KJ, Forster GL. Withdrawal from chronic amphetamine produces persistent anxiety-like behavior but temporally-limited reductions in monoamines and neurogenesis in the adult rat dentate gyrus. Neuropharmacology 2010; 59: 395-405

7. Cano E, Hazzalin CA, Kardalinou E, Buckle RS, Mahadevan LC. Neither ERK nor JNK/SAPK MAP kinase subtypes are essential for histone H3/HMG-14 phosphorylation or c-fos and c-jun induction. J Cell Sci 1995; 108 (Pt 11): 3599-3609.

8. Ceni C, Kommaddi RP, Thomas R, Vereker E, Liu X, McPherson PS, Ritter B, Barker PA. The p75 NTR intracellular domain generated by neurotrophin-induced receptor cleavage potentiates Trk signaling. I Cell Sci 2010; 123: 2299-2307.

9. Chadee DN, Hendzel MJ, Tylipski CP, Allis CD, Bazett-Jones DP, Wright JA, Davie JR. Increased Ser-10 phosphorylation of histone $\mathrm{H} 3$ in mitogen-stimulated and oncogene-transformed mouse fibroblasts. J Biol Chem 1999; 274: 24914-24920.

10. Cunha-Oliveira T, Rego AC, Cardoso SM, Borges F, Swerdlow RH, Macedo T, de Oliveira CR. Mitochondrial dysfunction and caspase activation in rat cortical neurons treated with cocaine or amphet amine. Brain Res 2006; 1089: 44-54.

11. Deisseroth K, Singla S, Toda H, Monje M, Palmer TD, Malenka RC. Excitation-neurogenesis coupling in adult neural stem/progenitor cells. Neuron 2004; 42: 535-552.

12. Duan X, Kang E, Liu CY, Ming GL, Song H. Development of neural stem cell in the adult brain. Curr Opin Neurobiol 2008; 18 108-115.

13. Eisch AJ, Barrot M, Schad CA, Self DW, Nestler EJ. Opiates inhibit neurogenesis in the adult rat hippocampus. Proc Natl Acad Sci U S A 2000; 97: 7579-7584.

14. Gascon E, Vutskits L, Kiss JZ. The role of PSA-NCAM in adult neurogenesis. Adv Exp Med Biol 2010; 663: 127-136.

15. Hyman C, Hofer M, Barde YA, Juhasz M, Yancopoulos GD, Squinto SP, Lindsay RM. BDNF is a neurotrophic factor for dopaminergic neurons of the substantia nigra. Nature 1991; 350: 230-232.

16. Kochman LJ, Fornal CA, Jacobs BL. Suppression of hippocampal cell proliferation by short-term stimulant drug administration in adult rats. Eur J Neurosci 2009; 29: 2157-2165.

17. Lewin GR, Barde Y. Physiology of the neurotrophins. Annu Rev Neurosci 1996; 19: 289-317.
18. Mahadevan LC, Willis AC, Barratt MJ. Rapid histone H3 phosphorylation in response to growth factors, phorbol esters, okadaic acid, and protein synthesis inhibitors. Cell 1991; 65: 775-783.

19. Mandyam CD, Wee S, Crawford EF, Eisch AJ, Richardson HN, Koob GF. Varied access to intravenous methamphetamine selfadministration differentially alters adult hippocampal neurogenesis. Biol Psychiatry 2008; 64: 958-965.

20. Ming GL, Song H. Adult neurogenesis in the mammalian central nervous system. Annu Rev Neurosci 2005; 28: 223-250.

21. Morgan JI, Curran T. Stimulus-transcription coupling in the nervous system: involvement of the inducible proto-oncogenes fos and jun. Annu Rev Neurosci 1991; 14: 421-451.

22. Noonan MA, Choi KH, Self DW, Eisch AJ. Withdrawal from cocaine self-administration normalizes deficits in proliferation and enhances maturity of adult-generated hippocampal neurons. J Neurosci 2008; 28: 2516-2526.

23. Ohira K, Furuta T, Hioki H, Nakamura KC, Kuramoto E, Tanaka Y, Funatsu N, Shimizu K, Oishi T, Hayashi M, Miyakawa T, Kaneko T, Nakamura S. Ischemia-induced neurogenesis of neocortical layer 1 progenitor cells. Nat Neurosci 2010; 13: 173-179.

24. Okano H, Sawamoto K. Neural stem cells: involvement in adult neurogenesis and CNS repair. Philos Trans R Soc Lond B Biol Sci 2008; 363: 2111-2122.

25. Pacak K, Palkovits M. Stressor specificity of central neuroendocrine responses: implications for stress-related disorders. Endocr Rev 2001; 22: 502e548.

26. Pluta R, Bogucka-Kocka A, Ułamek-Kozioł M, Furmaga-Jabłońska W, Januszewski S, Brzozowska J, Jabłoński M, Kocki J. Neurogenesis and neuroprotection in postischemic brain neurodegeneration with Alzheimer phenotype: is there a role for curcumin? Folia Neuropathol 2015; 53: 89-99.

27. Recinto P, Samant AR, Chavez G, Kim A, Yuan CJ, Soleiman M, Grant Y, Edwards S, Wee S, Koob GF, George O, Mandyam CD. Levels of neural progenitors in the hippocampus predict memory impairment and relapse to drug seeking as a function of excessive methamphetamine self-administration. Neuropsychopharmacology 2012; 37: 1275-1287.

28. Rodríguez JJ, Jones VC, Tabuchi M, Allan SM, Knight EM, LaFerla FM, Oddo S, Verkhratsky A. Impaired adult neurogenesis in the dentate gyrus of a triple transgenic mouse model of Alzheimer's disease. PLoS One 2008; 3: e2935.

29. Rotllant D, Márquez C, Nadal R, Armario A. The brain pattern of c-fos induction by two doses of amphetamine suggests different brain processing pathways and minor contribution of behavioural traits. Neuroscience 2010; 168: 691-705.

30. Rotllant D, Armario A. Brain pattern of histone H3 phosphorylation after acute amphetamine administration: its relationship to brain c-fos induction is strongly dependent on the particular brain area. Neuropharmacology 2012; 62: 1073-1081.

31. Russo-Neustadt AA, Alejandre H, Garcia C, Ivy AS, Chen MJ. Hippocampal brain-derived neurotrophic factor expression following treatment with reboxetine, citalopram, and physical exercise. Neuropsychopharmacology 2004; 29: 2189-2199.

32. Santarelli L, Saxe M, Gross C, Surget A, Battaglia F, Dulawa S, Weisstaub N, Lee J, Duman R, Arancio O, Belzung C, Hen R. 
Requirement of hippocampal neurogenesis for the behavioral effects of antidepressants. Science 2003; 301: 805-809.

33. Scharfman H, Goodman J, Macleod A, Phani S, Antonelli C, Croll S. Increased neurogenesis and the ectopic granule cells after intrahippocampal BDNF infusion in adult rats. Exp Neurol 2005; 192: 348-356.

34. Snyder JS, Hong NS, McDonald RJ, Wojtowicz JM. A role for adultneurogenesis in spatial long-term memory. Neuroscience 2005; 130: 843-852.

35. Taracha E, Hamed A, Krząścik P, Lehner M, Skórzewska A, Plaźnik A, Chrapusta SJ. Inter-individual diversity and intraindividual stability of amphetamine-induced sensitization of frequency-modulated 50-kHz vocalization in Spraguee Dawley rats. Psychopharmacology (Berl) 2012; 222: 619e632.

36. Tashiro A, Makino H, Gage FH. Experience-specific functional modification of the dentate gyrus through adult neurogenesis: a critical period during an immature stage. J Neurosci 2007; 27 3252-3259.

37. Teucherdt-Noordt G, Dawirs RR, Hidebrandt K. Adult treatment with methamphetamine transiently decreases dentate granule cell proliferation in the gerbil hippocampus. J Neural Transm 2000; 107: 133-143.

38. Thompson PM, Hayashi KM, Simon SL, Geaga JA, Hong MS, Sui $Y$, et al. Structural abnormalities in the brains of human subjects who use methamphetamine. J Neurosci 2004; 24 6028-6036.

39. Valjent E, Bertran-Gonzalez J, Aubier B, Greengard P, Hervé D, Girault JA. Mechanisms of locomotor sensitization to drugs of abuse in a two-injection protocol. Neuropsychopharmacology 2010; 35: 401-415.

40. Venkatesan A, Uzasci L, Chen Z, Rajbhandari L, Anderson C, Lee MH, Bianchet MA, Cotter R, Song H, Nath A. Impairment of adult hippocampal neural progenitor proliferation by methamphetamine: role for nitrotyrosination. Mol Brain 2011; 4: 28.

41. Wang JM, Brinton RD. Allopregnanolone-induced rise in intracellular calcium in embryonic hippocampal neurons parallels their proliferative potential. BMC Neurosci 2008; 9 Suppl 2: S11.

42. Xu H, Luo C, Richardson JS, Li XM. Recovery of hippocampal cell proliferation and BDNF levels, both of which are reduced by repeated restraint stress, is accelerated by chronic venlafaxine. Pharmacogenomics I 2004; 4: 322-331.

43. Yuan CJ, Quiocho JM, Kim A, Wee S, Mandyam CD. Extended access methamphetamine decreases immature neurons in the hippocampus which results from loss and altered development of neural progenitors without altered dynamics of the S-phase of the cell cycle. Pharmacol Biochem Behav 2011; 100: 98-108. 